\title{
EL EMPLEO TEMPORAL EN LA INDUSTRIA COLOMBIANA, $2000-2013^{*}$
}

\author{
Recibido: 21 de noviembre de 2015 • Aprobado: 08 de abril de 2016 \\ Edilberto Rodríguez Araújo** \\ Lina Marleny López Sánchez ${ }^{* *}$
}

\section{RESUMEN}

Este artículo analiza la evolución del empleo tmporal en la industria manufacturera de Colombia. La fuente de información es la encuesta anual manufacturera del Departamento Administrativo Nacional de Estadística. Para el análisis se utilizaron las series cronológicas de las principales variables del empleo manufacturero durante el período 2000-2013. Se encontró que la utilización del empleo temporal en la industria desde la década del noventa ha crecido a expensas del empleo permanente hasta representar, en 2013, el 41,4\%. Dentro de esta modalidad, y no obstante el crecimiento del empleo temporal indirecto en las diversas categorías funcionales, la contratación directa lo supera. De otra parte, el empleo masculino rebasó al femenino en todas las modalidades de contratación superando el 60 \%. El empleo temporal femenino directo, a pesar de su rápido descenso durante el período de análisis, superó en cinco puntos al indirecto en 2013.

\section{PALABRAS CLAVE}

Flexibilización laboral, industria manufacturera, tercerización, empleo temporal, contratación directa, contratación indirecta.

\section{CLASIFICACIÓN JEL}

\section{J46, 017}

\section{CONTENIDO}

Introducción; 1. Modelos tecnoproductivos y flexibilización laboral; 2. Flexibilización y tercerización laboral; 3. La reglamentación de la tercerización laboral en Colombia; 4. Desempeño reciente de la industria colombiana; 5. Estructura y tendencias del empleo industrial; 6. Conclusiones; Bibliografía.

* El artículo es una reflexión académica sobre uno de los fenómenos con mayor incidencia en la calidad del empleo generado en Colombia, el cual, sin embargo, no ha sido estudiado lo suficiente. Los autores, desde los grupos de investigación a que pertenecen en la Facultad de Ciencias Económicas y Administrativas de la UPTC, han venido indagando acerca de la aparición y evolución de la modalidad de contratación temporal, cuyos resultados pueden ser incorporados en programas de educación continuada y demás eventos académicos.

** Economista, Universidad Patricio Lumumba, Moscú, Rusia. Magíster en Economía, Universidad Nacional de Colombia, Bogotá, Colombia. Profesor de la Escuela de Economía, Universidad Pedagógica y Tecnológica de Colombia, Tunja, Colombia. Integrante del grupo de investigación Observatorio de Coyuntura Económica Regional y Urbana (OIKOS), Universidad Pedagógica y Tecnológica de Colombia, Tunja, Colombia. Correo electrónico: edilberto.rodriguez@uptc.edu.co; palimpsesto@hotmail.com.

*** Contadora Pública, Universidad de Boyacá, Tunja, Colombia. Magíster en Administración, Universidad de la Salle, Bogotá, Colombia. Profesora de la Escuela de Contaduría Pública, Universidad Pedagógica y Tecnológica de Colombia, Tunja, Colombia. Directora del grupo de investigación Dinámica Contable (GIDICON), Universidad Pedagógica y Tecnológica de Colombia, Tunja, Colombia. Correo electrónico: linalopezuptc@hotmail.com. 


\section{TEMPORARY EMPLOYMENT IN THE COLOMBIAN INDUSTRIAL, 2000-2013 ABSTRACT}

This article analyses temporary labor trajectory in the Colombian manufacturing industry. The source of information used for this purpose is the National Statistics Department Manufacturing Survey. For this analysis, the chronological series for the main manufacturing employment variables during the time period 2000-2013 where used. It was found that since the 90s, the use of temporary employment has grown at the expense of permanent labor, representing in $201441.4 \%$ of total employment. Despite the growth of indirect temporal employment, direct hiring represents a larger part of the pie. In the other had, men employment exceeded women employment in all categories over a 60\%. Direct women employment, despite its fast drop during the period of analysis was 5 points over indirect employment in 2013.

\section{KEY WORDS}

Labor flexibility, manufacturing industry, outsourcing, temporary employment, direct hiring, indirect hiring.

\section{JEL CLASSIFICATION}

J46, 017

\section{CONTENT}

Introduction; 1. Techno-productive models and labor flexibility; 2. Labor flexibility and outsourcing; 3. The regulation of labor outsourcing in Colombia; 4 . Recent performance of the Colombian industry; 5. Industrial employment trends and labor; Conclusions; Bibliography.

\section{EMPREGO TEMPORAL NA INDUSTRIA COLOMBIANA, 2000-2013 RESUMO}

Este artigo analisa a trajetória do emprego temporal na indústria manufatureira da Colômbia. A fonte de informação utilizada é a enquete anual manufatureira do Departamento Administrativo Nacional de Estadística (DANE). Para a análise se utilizaram as séries cronológicas das principais variáveis do emprego manufatureiro durante o período 2000-2013. Se encontrou que a utilização do emprego temporal desde a década dos anos noventa há crescido a expensas do emprego permanente até representar em 2013 $41,4 \%$. Dentro desta modalidade, no entanto o crescimento do emprego temporal indireto nas diversas categorias funcionais, a contratação direta o supera. De outra parte, o emprego masculino superou ao feminino em todas as modalidades de contratação superando $60 \%$. O emprego temporal feminino direto, no entanto seu rápido descenso durante o período de análise, superou em cinco pontos ao indireto em 2013.

\section{PALAVRAS CHAVE}

Flexibilização laboral, indústria manufatureira, terceirização, emprego temporal, contratação direta, contratação indireta.

\section{CLASSIFICAÇÃO JEL} J46, 017

\section{CONTEÚDO}

Introdução; 1. Modelos tecnoprodutivos e flexibilização laboral; 2. Flexibilizaçao e terceirização laboral; 3. A regulamentação da terceirização laboral na Colômbia; 4. Desempenho recente da indústria colombiana; 5. Estrutura e tendências do emprego industrial; 6. Conclusões; Bibliografia. 


\section{INTRODUCCIÓN}

Uno de los fenómenos contemporáneos de mayor propagación es la flexibilización laboral, que se remonta a la década de 1980. El tránsito en la década del 1970 del paradigma de organización de la producción y del trabajo fordista a uno posfordista o neofordista supuso una reestructuración de la organización de la producción y de las relaciones de trabajo, uno de cuyos subproductos es la tercerización en la contratación de la mano de obra que cobija todos los sectores de la economía mundial, aún con más severidad en la condiciones de cambio estructural en América Latina y Colombia que ha transformado sus perfiles productivos, tal como lo sugiere Durán (2012).

Bajo las nuevas condiciones, los trabajadores se enfrentan a cambios en las funciones y roles, y de manera simultánea, a estrategias empresariales de adaptación tanto al nuevo entorno competitivo (fluctuaciones de la demanda) como a las exigencias de la modernización de la estructura fabril (requerimientos de polivalencia funcional). El resultado será la movilidad y rotación de la mano de obra, a la par que las diferencias salariales y, finalmente, la precarización de las condiciones de trabajo.

La reducción de la protección del trabajo que representa la flexibilización laboral ha ido de la mano de la desregulación neoliberal, bajo el argumento de la existencia de rigideces que frenan los aumentos de la productividad y de la competitividad. La regulación de las diversas modalidades de empleo temporal ha ido a la zaga de la dinámica laboral, siendo frecuente los atajos de los empleadores para evadir las normas restrictivas ante unas diezmadas organizaciones sindicales.

La contratación temporal tiene dos vertientes: la primera la hace el empleador directamente; la segunda, de manera indirecta, a través de terceros o intermediarios (empresas de servicios temporales, cooperativas de trabajo asociado, empresas asociativas de trabajo, entre otras figuras), decisión motivada por factores asociados a los costos de enganche o extralaborales.

El interés académico por el estudio del comportamiento de la temporalidad del trabajo obedece a la creciente importancia que esta modalidad ha adquirido, al transformar la composición de la demanda de empleo en un sector atravesado por las transformaciones derivadas de los ciclos económicos, como es la industria manufacturera, afectada, además, por una desindustrialización temprana. La sustitución de trabajo permanente por temporal, directo o indirecto, revela la adaptación de los establecimientos manufactureros a los cambios en el entorno empresarial, lo que, indudablemente, afecta la calidad del empleo'.

Las estadísticas sobre este fenómeno en América Latina no son abundantes. La Confederación Sindical de Trabajadores y Trabajadores (CSA) conjuntamente con la Confederación Internacional (CSI) (2013) 
El presente artículo busca explorar las características más relevantes del empleo temporal de la industria colombiana, haciendo énfasis en las categorías funcionales de la producción, como trabajadores, operarios y empleados; ingenieros, técnicos y tecnólogos, y aquellas dedicadas a las áreas de administración y ventas. De igual forma, se incluye una aproximación de la influencia del género de los trabajadores contratados en el empleo temporal. La información básica utilizada para el análisis es la proveniente de la encuesta anual manufacturera (EAM), divulgada por el Departamento Administrativo Nacional de Estadística (DANE). El período escogido corresponde al intervalo 2000-2013.

En el texto se analiza el comportamiento del empleo industrial en el período 2000-2013, así como su composición y principales tendencias. Del análisis se desprende el aumento sostenido del empleo temporal, en particular, la contratación a término fijo de obreros y operarios de género masculino. Al finalizar el período de referencia se han observado algunos indicios de reversión de la tercerización, que apuntan a garantizar una relativa estabilidad laboral.

El trabajo se divide en cinco secciones a partir de la introducción: el primer acápite es una caracterización de los cambios en la organización de la producción y del trabajo; la segunda parte describe el fenómeno de las flexibilización y consiguiente tercerización laboral; el tercer apartado es un recuento del contexto legal en que esta se desenvuelve, y, la cuarta sección está centrada en un análisis pormenorizado del comportamiento y tendencias recientes del empleo industrial en Colombia. En la quinta sección se incluyen algunas conclusiones.

\section{MODELOS TECNOPRODUCTIVOS Y FLEXIBILIZACIÓN LABORAL}

El análisis del auge y decadencia de los modelos de organización de la producción y del trabajo, en la mayoría de los casos -como se presenta a continuación- están caracterizados por factores económicos y sociológicos. De allí, que los enfoques teóricos que desbordan los estrechos marcos economicistas (adaptación a un entorno competitivo), como la flexibilización, que supone la transformación de las relaciones laborales, permiten una mejor comprensión de este fenómeno, subproducto de la tercerización.

De la Garza (2012) y Neffa (1999) plantean que el desmonte del modelo tecnoproductivo fordista-taylorista en la década de 1970 coincide con la aceleración del

publicaron el libro Tercerización mediante agencias de trabajo temporal en América Latina, donde se incluyen ocho estudios sobre igual número de países (Argentina, Brasil, Chile, Colombia, México, Panamá, Perú y Uruguay), mostrando la importancia que ha adquirido estas formas de contratación y los intentos reguladores desplegados por los gobiernos. 
cambio estructural, tal como lo reconocen Katz (2007), Moncayo $(2008)^{2}$ y la OIT (2015), por consiguiente, con la desindustrialización catalogada como prematura y espuria por autores como Clavijo, Vera y Fandiño (2012; 2013), Moncayo (2011), Rodríguez (2010) y Salama (2012), y que, a juicio de Añez (2012) y Quevedo (2000) es jalonada por la globalización y la dislocación geográfica de los procesos productivos. Según Baró (2013, p. 40), esta puede definirse como:

Una nueva configuración de las cadenas de valor de los principales bienes industriales con una mayor fragmentación (y modularización) de los procesos de producción y con una más extensa diversificación de la localización espacial de las distintas etapas del proceso productivo (y con la exigencia de mayores-y más expertas -capacidades de integración de dichos procesos en aquellas firmas que ocupan el eslabón clave de la cadena.

Así, la reestructuración productiva derivada del cambio de paradigma, estuvo aparejada de la flexibilización de las relaciones laborales. En esa perspectiva González (2006, p. 37) precisa que "El fordismo es un concepto que tiene dos acepciones: [...] la cadena de montaje como parte de la organización del trabajo asociada al taylorismo [...] la organización social que vincula la producción en masa con el consumo en masa [...]".

La transición hacia el modelo de organización de la producción y del trabajo posfordista o especialización flexible no ha sido simultánea ni uniforme-su momento de auge y decadencia se sitúa entre finales del Siglo XX y comienzos del Siglo XXI-, afirmándose que los dos grandes paradigmas coexisten, pese a la prevalencia de uno sobre el otro; lo anterior, sin aludir a la aparición del neofordismo o el toyotismo, como paradigma organizacional, tal como lo manifiestan De la Garza (2012) y Safón (1997), además de nuevas formas de aglomeración industrial como los distritos industriales italianos.

Para Clavijo, Vera y Fandiño (2012) la producción y reproducción capitalista está ligada a la tercera Revolución Industrial o manufactura digital, basada en la revolución microelectrónica que se extendió en las últimas dos décadas del siglo pasado con las tecnologías de la información y las comunicaciones (TIC), cuyo origen es el surgimiento de Internet en los noventa. No resulta una mera coincidencia que ello se articule con el período de ascenso del neoliberalismo y con la búsqueda de estrategias como la reestructuración productiva para remontar la crisis capitalista, según lo concluye De la Garza (2012).

Según Moncayo (2008) el proceso de cambio estructural no sólo implica transformación de la oferta productiva, sino también de la demanda de trabajo y del nivel de ingreso, resultado de la recomposición sectorial. 
González (2006, p. 43) define la flexibilización laboral "desde el punto de vista de la empresa como las estrategias realizadas por esta para adaptarse al mercado, y desde el punto de vista del trabajador, como la mayor disposición de manera concertada a adaptarse a las nuevas y mayores tareas"; a ello se puede agregar que la sindicalización es mal vista y peor tratada en este proceso desregulador que debilita la cohesión, rompiendo los vínculos de solidaridad, debido a que en palabras de Iranzo y Richter (2012, p. 54):

Los sindicatos no tienen muchas posibilidades de defender a estos trabajadores, no solo porque no están oficialmente afiliados sino, además, porque uno de los rasgos de los mecanismos de subcontratación laboral es su carácter ambiguo e indeterminado mediante el cual no queda claramente definida la figura que ejerce la responsabilidad patronal y frente a la cual habrían de formularse las quejas o demandas correspondientes.

Asimismo, González (2006) propone una clasificación, tanto de flexibilización laboral ${ }^{3}$ como de los abordajes teóricos en el marco de los modelos tecnoproductivos, entre los que se encuentran los siguientes enfoques: la economía neoclásica, la nueva ola gerencial, y el posfordismo (corrientes regulacionista, institucionalista o especialización flexible y neoschumpeteriana), que suponen un perfil diferenciado de los trabajadores y cambios sustanciales en el mercado de trabajo.

La modernización empresarial posfordista, y su concomitante flexibilización del trabajo, trajo consigo relaciones laborales temporales y flexibles, al basarse en una fuerza laboral contingente, polivalente, inestable, rotativa e informal, y propiciar, lo que es catalogado por González (2006, p. 62) como "una subcontratación o flexibilización externa" que configura la tercerización empresarial.

El modelo convencional del empleo entró en declive, como lo reconoce la OIT (2015, p. 1), al subrayar que "se ha producido un alejamiento con respecto al modelo estándar de empleo, en cuyo marco los trabajadores perciben un sueldo o un salario en una relación de empleo dependiente con respecto a sus empleadores, tienen un trabajo estable y trabajan a tiempo completo".

Adicionalmente, la OIT $(2015$, p. 1) hace hincapié en que el resquebrajamiento del llamado modelo estándar de empleo se expresa en el hecho de que "menos del $45 \%$ de los trabajadores asalariados tienen un empleo a tiempo completo y permanente"; agrega esta organización que "Esto significa que, en todo el mundo cerca de 6 de cada 10 trabajadores asalariados están ocupados en formas de empleo a tiempo parcial o temporal", es decir, que "menos de uno de cada cuatro trabajadores está empleado hoy en condiciones que corresponden a este modelo".

\footnotetext{
González (2006, p. 46) enumera seis formas de flexibilización: 1) Flexibilidad numérica, 2) Flexibilidad de la organización del trabajo, 3) Flexibilidad funcional, 4) Flexibilidad salarial, 5) Flexibilidad contractual. y, 6) Flexibilidad cualitativa.
} 
El empleo temporal, llamado por Echeverría (2001) como temporario, eventual, transitorio o contingente, según González y Cuello (2007), se ha expandido en Europa, Norteamérica, América Latina y el Caribe. El empleo temporal se estudia, desde el manejo de recursos humanos, por los siguientes enfoques: la teoría de recursos y capacidades, la teoría de agencia y la teoría de costos de transacción.

Bajo esa forma de contratación, la empresa no asume ninguna responsabilidad contractual, y la agencia intermediaria actúa discrecionalmente, basándose en la eficiencia. Por último, los costos de transacción, enfoque propio de la nueva economía institucional, postulan que la rotación de personal podría generar menores costos de transacción debido a la flexibilidad empresarial; sin embargo, tal como acontece con el acatamiento de los derechos de propiedad, pese a que los contratos, como la información que los nutre, son incompletos, el contratante procura minimizar los riesgos con el contratado, por la dinámica de la movilidad laboral. De la Garza (2012, p. 29) cuestiona estas teorías porque "no consideran el problema de la acumulación de capital a escala mundial y si se ha entrado en una etapa superior de subcontratación como uno de sus ejes; además de que no fueron hechas en particular para la subcontratación, son teorías generales sobre empresas".

Ariza (2011), Echeverría (2001); González y Cuello (2007) y Parra (2012), ante el interrogante de ¿cuáles son los móviles que inducen a la contratación temporal?, identifican factores tales como:

1. Los costos laborales -teniendo como referente el salario mínimo-y los costos no salariales, como las contribuciones parafiscales a las nómina y a la seguridad social;

2. Los costos de inclusión en la nómina (contratación) y de despido (indemnización);

3. La sustitución de trabajo permanente por trabajo temporal o trabajo indirecto a término fijo, mediante la externalización y subcontratación;

4. La percepción de los empresarios sobre los costos de sindicalización de los trabajadores;

5. Los ciclos económicos y su incidencia en la recomposición de la demanda de trabajo;

6. Los ajustes del mercado laboral que contrarrestan el desempleo (entrada y salida hacia y desde el desempleo); 
7. Los niveles de productividad, derivados de la composición de la mano de obra, que inciden en el desempeño empresarial;

8. La flexibilidad organizativa frente a la incertidumbre asociada al cambio tecnológico y nuevas formas de competitividad;

9. La respuesta racional de la empresa ante los cambios dentro y fuera de la misma, con particular énfasis en el mercado de trabajo;

10. La presión en el nivel corporativo para reducir los costos laborales.

Por último, la heterogeneidad estructural, como lo ha postulado Ramírez (2011), ha provocado un mercado del trabajo segmentado y diferenciado, a tono con los requerimientos de las empresas que buscan apropiarse de nichos de mercado de bienes y servicios, en medio de la más feroz competencia intrafirmas. Así, en la medida en que el espectro económico se diversifica, los trabajadores temporales se han tornado en una fuente expedita de mano de obra. Para De la Garza (2012) el empleo temporal se ha convertido en un rasgo típico de una economía globalizada, en las que las firmas, como lo plantean Romo y Musik (2005), buscan aprovechar las ventajas competitivas.

\section{FLEXIBILIZACIÓN Y TERCERIZACIÓN LABORAL}

La reestructuración productiva y la reorganización del trabajo han transformado la relación laboral típica ${ }^{4}$, que ahora está acompañada de una modalidad emergente, definida por Sánchez (2012, p. 3) como "la forma de contratación de la fuerza de trabajo donde no existe una relación de dependencia entre el contratante y el contratado, y existe un intermediario entre las partes, por lo que es equivalente a la externalización o tercerización del trabajo". Añez (2012) denomina esta estrategia de externalización triangulación laboral, cuya matriz organizacional es la subcontratación u outsourcing, que conduce a relaciones laborales encubiertas. A esta megatendencia no escapa la Administración Pública de muchos países que han dado cabida en la nómina estatal a esta forma de vinculación laboral.

De acuerdo con la ONUDI (2013, p. 17) "Los procesos de transformación estructural no se detienen en la frontera entre la industria manufacturera y la de servicios", por el contrario, la industria manufacturera ha fragmentado sus procesos y transformado su perímetro;

4 González (2006, p. 41) puntualiza que "la relación laboral es la relación entre capital y trabajo en el centro de la producción".

5 Las áreas donde se ha propagado la tercerización son las llamadas transversales o no misionales, tales como ventas y servicios, operadores de máquinas, obreros, labores de oficina, contabilidad, aseo, vigilancia, servicios financieros, entre otras. 
muchas de sus actividades han migrado al sector servicios, surgiendo, a juicio de Baró (2013), una nueva industria.

Para la OIT (2015, p. 18), la fragmentación se concibe como

[...] la incorporación de mayor valor y productividad en áreas tales como marketing, investigación y desarrollo e ingeniería y dichos cambios pueden interpretarse como la siguiente fase de transformación estructural y generación de empleo para las economías de ingresos más altos.

Contrario a la interpretación predominante, Ariza (2011, p. 20) considera que

[...] la temporalidad y la tercerización en el mercado laboral debe entenderse como parte de un ciclo natural, ya que tanto la economía mundial como la colombiana, están afrontando cambios en las relaciones de producción y, por ende, en las relaciones laborales.

Este fenómeno, resultante del modelo de crecimiento implantado, acarreó, en el caso colombiano, un sesgo antilaboral, que ha tenido efectos perjudiciales. Pineda (2014, p. 1) afirma que

La externalización de actividades productivas (outsourcing) y la tercerización de trabajadores consolidaron un esquema que para la industria y la agroindustria significó cerca de la mitad de los trabajadores en empleos inestables o precarios [...] la tercerización se presenta también como deslaboralización de las relaciones de trabajo con la utilización creciente de los contratos de prestación de servicios.

Pineda (2014) y Vásquez (2013) sostienen que la tercerización laboral ha venido expandiéndose de manera acelerada desde comienzos de la década de 1990 en Colombia, lo que coincidió con la apertura neoliberal, en sintonía con el Consenso de Washington, por lo que, para regular estas relaciones trabajador-contratistaempresa intermediaria contratante, se ha adoptado una normativa que ha buscado reglamentar su funcionamiento, lo que ha favorecido la posición dominante del empleador en el mercado de trabajo.

La ANDI (2015, p. 80), plantea que la tercerización es "uno de los elementos de la flexibilización laboral y ha sido definida como el proceso por medio del cual se transfieren actividades dentro de la cadena de valor a proveedores seleccionados, los cuales actúan con plena independencia".

El estudio de esta faceta del mercado de trabajo no ha sido suficientemente abordado en la literatura económica en Colombia; por ello, en línea con lo encontrado por Parra (2012), un estudio adelantado por ACRIP y Fedesarrollo (2013, p. 4) reconocen que:

El análisis de la tercerización laboral en Colombia ha estado relativamente marginado del interés académico y político. En efecto, la investigación del mercado 
laboral colombiano se ha centrado principalmente en el estudio de los determinantes del desempleo y la informalidad.

Diversos son los móviles que llevan a los empleadores a recurrir a esta forma de contratación. Al respecto ACRIP y Fedesarrollo (2013, p. 3) establecieron que:

[...] una de las principales motivaciones de la tercerización del trabajo es la de facilitar aumentos transitorios en la fuerza laboral ante expansiones no permanentes en la actividad económica de las empresas, las cuales pueden estar dadas por la época del año, el ciclo económico o por oportunidades aisladas de negocio.

En el estudio mencionado ACRIP y Fedesarrollo (2103, p. 3) agregan que:

[... .] una segunda razón para la tercerización es la necesidad de las compañías de focalizar esfuerzos en sus actividades misionales, dejando la especialización de las áreas de apoyo en cabeza de otras compañías, que pueden prestar estos servicios con una mayor escala, eficiencia en precios y calidad.

Ahora bien, el sector industrial colombiano, como las demás economías latinoamericanas, ha afrontado un retroceso en las últimas décadas, que ha sido analizado por Clavijo, Vera y Fandiño (2012) y cuyas consecuencias fueron reveladas por la ANDI (2015). La desindustrialización así denominada, según Pineda (2014, p. 14), desembocó en "una reestructuración productiva que basa su competitividad en la subcontratación y reducción de costos laborales a partir de la flexibilización laboral".

La recomposición de la demanda de trabajo a favor del empleo temporal se da, como lo afirma Pineda (2014, p.14), a comienzos de la década del noventa, cuando "se inicia un proceso intensivo de externalización de actividades productivas (outsourcing) y de tercerización de trabajadores".

Esta tendencia se ha acentuado, reduciendosé el empleo a término indefinido o permanente, llevando a que la duración de los contratos se torne cada vez más reducida, mostrando que la tercerización y la subcontratación resultante se haga por periodos de tres, seis meses o un año, a través de las empresas de servicios temporales $(\mathrm{EST})^{6}$ y las cooperativas de trabajo asociado (CTA) ${ }^{7}$.

6 En 2012 ACOSET (2012, p. 7) reportó 595.590 trabajadores en misión, dentro de los cuales el sector industrial representaba el 23,8 \%. Otros estudios como Ariza (2011) y Pineda (2014) calculan que el medio millar de EST registradas emplean entre 1 millón y 1.5 millones de personas. Según el Ministerio de Trabajo a marzo de 2015 el registro vigente de EST activas, entre principales y sucursales, era de 873 empresas. Asimismo, este ministerio reveló que en el periodo 2003-2013 la demanda de trabajo (colocaciones), a través de las EST pasó de 401.797 a 433.898 personas, descendiendo la proporción de la industria manufacturera de 129.733 a 121.807 contratados.

7 El número de CTA en 2012, según registros de Confederación de Cooperativas de Colombia (Confecoop, 2012), ascendió a 2.890. Es paradójico que esta modalidad de organización cooperativa, pese a representar el 44,5\% de las entidades cooperativas sólo aporta el 7\% de los afiliados. Es muy ilustrativo que el $98 \%$ de estas cooperativas se dedicaban a los servicios. Cabe recordar que en ese año el número 
Quizá lo más preocupante es que esta última figura, en que se anidan los contratos de prestación de servicios y otras categorías de trabajadores como estacionales o de temporada, por obra o a destajo, condujo a la aparición de un fenómeno de precarización y conflictividad, que es la deslaboralización de las relaciones de trabajo, que se manifiesta, de acuerdo con Pineda (2014, p. 16), cuando un tercero "vincula a los trabajadores como asociados cooperativos, para trabajar en las empresas contratantes; de esta manera se establece un contrato comercial de prestación de servicios entre la empresa y el CTA que elude la relación laboral".

Como la flexibilidad laboral se ha incorporado a la organización de la producción industrial, la ANDI (2015, p. 78), desvirtúa su presunto carácter episódico, afirmando que

[...] esta flexibilidad no responde a fenómenos cíclicos o temporales: se trata de transformaciones estructurales que exigen, en consecuencia, un cambio en la gestión y estrategia empresarial. Para responder a estas nuevas condiciones económicas, el empresario debe estar en condiciones de ajustar la organización interna de su empresa.

Es indudable que esta agremiación promueve una estrategia adaptativa de los empresarios en las condiciones cambiantes de su entorno competitivo, lo que, para De la Garza (2012, p. 15), ocurre porque "el entorno no es lo externo simplemente sino lo externo internalizado en el objeto que puede cambiar su significado".

\section{LA REGLAMENTACIÓN DE LA TERCERIZACIÓN LABORAL EN COLOMBIA}

Analizando la experiencia latinoamericana en la que el derecho al trabajo ha quedado relegado, Iranzo y Richter (2012, p. 40) anotan que las "reformas laborales facilitaron tanto el uso de la intermediación, como la utilización de otros mecanismos que le permitieron a las empresas escapar a la sanción de la legislación del trabajo y a la vez posibilitaron una disminución de las responsabilidades patronales".

El marco regulatorio adoptado en Colombia, y que tiene como eslabón principal el Código Sustantivo de Trabajo (CST), es muy denso. En la búsqueda de flexibilizar la contratación -escrita o verbal- de la mano de obra para acoplarla con el crecimiento económico, la eficiencia y la competitividad, la legislación ha incurrido en ambigüedad y laxitud, lo que implica desprotección de los derechos de los trabajadores.

La ANDI (2015, p. 78), desde la perspectiva de gremio patronal, reconoce las limitaciones normativas existentes, poniendo en evidencia que "La legislación laboral, por su parte, tiende a ajustarse a condiciones de eficiencia económica", lo que se concibe, por supuesto, en el contexto de las estrategias de las empresas orientadas hacia las

de cooperativas existentes era de 6.421 y 6.541 .080 afiliados. 
llamadas por De la Garza (2012) como "cadenas globales de valor", que no es otra cosa que una estrategia emergente de expansión del capitalismo transnacional.

Pese a que la ANDI (2015, p. 80), como agremiación de los industriales colombianos cataloga a la tercerización laboral como lícita, subrayan que "Solo es censurada cuando, mediante la ambigüedad o el disfraz, el empleador evade las obligaciones que le corresponden $y$, consecuentemente, desconoce los derechos de sus empleados y colaboradores".

Las diversas figuras a través de las cuales operan los intermediarios laborales, en particular las cooperativas de trabajo asociado -tal como lo puso en evidencia López (2010)-, cuyo auge se registró en la década de 1990, son las mayores transgresoras, por lo que las normas expedidas en los últimos años han buscado establecer una regulación más estricta, fijando prohibiciones a la intermediación laboral.

Según Vásquez (2013, p. 4)

[...] existe un abuso generalizado de la subcontratación de personas a través de EST [...] como estrategia de las empresas para reducir sus costos [...], lo que les da la libertad de enganchar y desenganchar trabajadores de acuerdo con sus necesidades y sin ninguna sujeción a la regulación que al respecto establece la ley.

De otra parte, ACRIP y Fedesarrollo (2013, p. 5) destacan el desbordamiento de las restricciones del empleo temporal, al enfatizar que "en los últimos años el marco institucional permitió que las cooperativas de trabajo usaran la figura de la tercerización para establecer relaciones laborales que no estuvieron contempladas en su concepción seminal".

Finalmente, para evitar la tentación de ilegalidad, Ariza (2011, p. 22) plantea que "debe considerarse la posibilidad de ajustar la legislación para disminuir los incentivos a que, en su afán por racionalizar los costos, los empresarios empleen mecanismos que vayan en contra del marco regulatorio".

En la tabla 1 se presenta un resumen de la legislación laboral expedida desde 1990, punto de inflexión en la flexibilización del mercado de trabajo, al propiciar nuevas formas de contratación laboral a término fijo, como son el empleo temporal y la subcontratación:

Tabla 1. Resumen del marco regulatorio vigente en Colombia

\begin{tabular}{|l|l|}
\hline \multicolumn{1}{|c|}{ NORMA } & \multicolumn{1}{c|}{ ALCANCE } \\
\hline Código Sustantivo del Trabajo (CST) & $\begin{array}{l}\text { Artículos 23, 37, 46. 47: Contratos de trabajo y su duración. } \\
\text { Artículo 482: Contrato sindical. }\end{array}$ \\
\hline Ley 50 de 1990 & $\begin{array}{l}\text { Reforma al CST. Artículos 71, 74, 77: Contratación a } \\
\text { término fijo de servicios temporales con terceros (EST)/ } \\
\text { trabajadores en misión. }\end{array}$ \\
\hline
\end{tabular}


El empleo temporal en la industria colombiana, 2000-2013

\begin{tabular}{|c|c|}
\hline NORMA & ALCANCE \\
\hline Ley 60 de 1990 & Reglamentación escala salarial. \\
\hline $\begin{array}{l}\text { Decreto } 468 \text { de } 1990 \text { (Derogado por } \\
\text { el Decreto } 4588 \text { de 2006) }\end{array}$ & $\begin{array}{l}\text { Creación de cooperativas de trabajo asociado (CTA) como } \\
\text { asociaciones sin ánimo de lucro. }\end{array}$ \\
\hline Ley 10 de 1991 & Creación de las empresas asociativas de trabajo (EAT). \\
\hline Ley 100 de 1993 & $\begin{array}{l}\text { Nuevo régimen de seguridad social. Separación de los } \\
\text { aportes para salud y pensión. Eliminó el despido de } \\
\text { trabajadores con antigüedad. }\end{array}$ \\
\hline Ley 789 de 2002 & $\begin{array}{l}\text { Estímulos a la creación de puestos de trabajo mediante } \\
\text { aumento de la jornada de trabajo diurno y reducción de } \\
\text { costos. }\end{array}$ \\
\hline Ley 797 de 2003 & $\begin{array}{l}\text { Cotización de seguridad social (salud y pensión) en los } \\
\text { contratos de prestación de servicios. }\end{array}$ \\
\hline Decreto 4369 de 2006 & $\begin{array}{l}\text { Artículos 5, 6, 74, 94: Control a las empresas de servicios } \\
\text { temporales. }\end{array}$ \\
\hline $\begin{array}{l}\text { Decreto } 4588 \text { de } 2006 \text { (modificado } \\
\text { por el Decreto } 2417 \text { de 2007) }\end{array}$ & $\begin{array}{l}\text { Reglamentación de la organización y funcionamiento de } \\
\text { las cooperativas de trabajo asociado. }\end{array}$ \\
\hline Ley 1221 de 2008 & Promoción y regulación del teletrabajo. \\
\hline Ley 1429 de 2010 & $\begin{array}{l}\text { Formalización y generación de empleo. Reducción cargas } \\
\text { tributarias. Art. 63: Contratación de personal para ac- } \\
\text { tividades no misionales a través de las cooperativas de } \\
\text { trabajo asociado. }\end{array}$ \\
\hline Ley 1607 de 2012 & Eliminación de los impuestos a la nómina (ICBF y Sena). \\
\hline Ley 1610 de 2013 & Inspección sobre conductas abusivas en la tercerización. \\
\hline
\end{tabular}

Fuente: elaboración propia

\section{DESEMPEÑO RECIENTE DE LA INDUSTRIA MANUFACTURERA}

En las últimas dos décadas, el comportamiento del sector industrial colombiano ha sido cambiante, y ha presentado varios puntos de quiebre, en las variables número de establecimiento y empleo $(1997,2003$, 2008). Pese a que en el año 2009 cuando se desató una crisis internacional el número de unidades productivas se incrementó, el empleo y el producto industrial se contrajeron (tabla 2). Por el contrario, tanto la producción bruta manufacturera como el valor agregado han mostrado un aumento creciente, lo que se explica por mayores niveles de productividad del trabajo, la cual se cuadriplicó durante el periodo 1997-2013. 
Edilberto Rodríguez Araújo - Lina Marleny López Sánchez

Tabla 2. Comportamiento de las variables básicas de la industria manufacturera colombiana ${ }^{8}$

\begin{tabular}{|c|c|c|c|c|c|}
\hline Año & $\begin{array}{c}\text { N. } \text { de }_{\text {establecimientos }} \\
\text { total }\end{array}$ & $\begin{array}{c}\text { Personal ocupado } \\
\text { Producción Bruta } \\
\text { (miles de \$) }\end{array}$ & $\begin{array}{c}\text { Valor Agregado (miles } \\
\text { de \$) }\end{array}$ & $\begin{array}{c}\text { Productividad } \\
\text { laboral por } \\
\text { persona (miles } \\
\text { de \$) }\end{array}$ \\
\hline 1997 & 8320 & 630.588 & 42.078 .346 .840 & 19.049 .470 .430 & 30.209 .1 \\
\hline 1998 & 7861 & 592.956 & 47.596 .087 .144 & 21.730 .789 .114 & 36.648 .2 \\
\hline 1999 & 7441 & 533.340 & 48.569 .716 .987 & 22.360 .842 .545 & 41.926 .1 \\
\hline 2000 & 7246 & 534.573 & 61.036 .605 .397 & 26.744 .216 .509 & 50.029 .1 \\
\hline 2001 & 6960 & 528.022 & 68.196 .509 .877 & 29.507 .297 .033 & 55.882 .7 \\
\hline 2002 & 6881 & 531.213 & 74.947 .634 .467 & 32.756 .868 .974 & 61.664 .3 \\
\hline 2003 & 7230 & 545.897 & 87.329 .291 .668 & 37.083 .322 .355 & 67.919 .8 \\
\hline 2004 & 7249 & 570.855 & 100.110 .385 .674 & 42.655 .676 .818 & 74.722 .4 \\
\hline 2005 & 7524 & 587.630 & 108.340 .147 .335 & 46.513 .886 .253 & 79.155 .1 \\
\hline 2006 & 7369 & 612.080 & 126.694 .525 .578 & 55.433 .954 .175 & 90.566 .5 \\
\hline 2007 & 7257 & 637.621 & 139.189 .799 .013 & 61.469 .417 .083 & 96.404 .3 \\
\hline 2008 & 7937 & 652.854 & 149.750 .141 .148 & 65.014 .561 .489 & 99.585 .1 \\
\hline 2009 & 9135 & 641.444 & 144.225 .915 .575 & 64.669 .332 .622 & 100.818 .4 \\
\hline 2010 & 9946 & 665.556 & 156.527 .707 .423 & 67.802 .873 .941 & 101.874 .0 \\
\hline 2011 & 9809 & 679.926 & 192.937 .240 .465 & 76.338 .526 .321 & 112.274 .8 \\
\hline 2012 & 9488 & 676.425 & 199.767 .797 .209 & 75.865 .747 .833 & 112.156 .9 \\
\hline 2013 & 9227 & 676.883 & 203.809 .695 .355 & 78.832 .316 .210 & 116.463 .9 \\
\hline
\end{tabular}

Fuente: Elaboración propia con base en la encuesta anual manufacturera del DANE

La trayectoria seguida por las dos variables principales no guarda una relación directa que lleve a configurar un patrón típico, lo que puede atribuirse a la incorporación de procesos con mayor intensidad tecnológica, ahorradores de mano de obra. En concordancia con lo anterior, la productividad laboral exhibe un oscilante comportamiento (tabla 3). Sin embargo, no obstante que no registra caídas severas, en los últimos años -en particular desde finales de la década de 1990-su crecimiento ha sido lento e inferior al observado a comienzos de los años 2000.

\footnotetext{
8 Se incluye en las tablas iniciales información anterior al periodo de referencia para conocer el desempeño del sector industrial a finales del siglo XX.
} 
Tabla 3. Variación interanual de las de las variables básicas de la industria manufacturera colombiana (\%)

\begin{tabular}{|c|c|c|c|}
\hline Año & Personal ocupado total & Producción bruta & Productividad laboral \\
\hline 1998 & 6,0 & 11,7 & 21,3 \\
\hline 1999 & $-10,0$ & 2,0 & 14,4 \\
\hline 2000 & 0,2 & 25,7 & 19,3 \\
\hline 2001 & $-1,2$ & 11,7 & 11,7 \\
\hline 2002 & 0,6 & 9,9 & 10,3 \\
\hline 2003 & 2,8 & 16,5 & 10,1 \\
\hline 2004 & 4,6 & 14,6 & 10,0 \\
\hline 2005 & 2,9 & 8,2 & 5,9 \\
\hline 2006 & 4,2 & 16,9 & 14,4 \\
\hline 2007 & 4,2 & 9,9 & 6,4 \\
\hline 2008 & 2,4 & 7,6 & 3,3 \\
\hline 2009 & $-1,7$ & $-3,7$ & 1,2 \\
\hline 2010 & 3,7 & 8,5 & 1,0 \\
\hline 2011 & 2,1 & 23,3 & 10,2 \\
\hline 2012 & $-0,5$ & 3,5 & $-0,1$ \\
\hline 2013 & 0,1 & 2,0 & 3,8 \\
\hline
\end{tabular}

Fuente: elaboración propia con base en la encuesta anual manufacturera del DANE.

\section{ESTRUCTURA Y TENDENCIAS DEL EMPLEO INDUSTRIAL}

Como se puso de manifiesto atrás, el empleo temporal es una manifestación del trabajo no asalariado a término fijo, con una duración menor a un año, integrado por empleo temporal directo y empleo temporal indirecto (trabajo en una empresa diferente a la contratante) en actividades ocasionales, transitorias o accidentales, reemplazos y licencias, entre otras.

Así las cosas, los trabajadores temporales son, de acuerdo con a Fedesarrollo (2011, p. 6) "todos aquellos que tienen contrato de trabajo escrito por un término menor o igual a 12 meses. Por oposición, los permanentes son aquellos con contrato escrito a término indefinido". Es decir, además de los contratados directamente por los establecimientos industriales, están los contratados a través de las empresas de servicios temporales (EST), las cooperativas de trabajo asociado (CTA) y las empresas asociativas de trabajo (EAT) ${ }^{10}$.

9 En algunos países se denominan Empresas de Trabajo Temporal (ETT), definidas por Echeverría (2001, p. 7) como "empresas constituidas con la finalidad de proveer personal a otras".

10 A estas tres modalidades de contratación temporal se suman los criticados contratos sindicales. La modalidad dominante son las EST, seguida de las CTA y EAT. 
El uso del empleo temporal per se no es ventajoso. Su excesiva utilización trae desventajas, pues, de un lado, afecta la eficiencia de la empresa, y, del otro lado, propicia la precarización laboral, degradando las condiciones de empleo, cuando en la actual coyuntura se reclama, como lo califica Farné (2012), un empleo digno o decente. La existencia de un marco regulatorio no ha impedido que los intermediarios laborales vulneren los derechos de los trabajadores contratados.

A juicio de Fedesarrollo (2011, p. 8) "las condiciones laborales de estos trabajadores parecen ser precarias" o, en todo caso, inferiores a las de sus contrapartes permanentes y directos.

De esa forma, los trabajadores temporales pueden ser contratados directa o indirectamente; bajo esta última modalidad los establecimientos efectúan la contratación a través de las agencias de intermediación ${ }^{11}$.

Tabla 4. Estructura del empleo industrial colombiano ${ }^{12}$

\begin{tabular}{|c|c|c|c|c|c|c|}
\hline \multirow{2}{*}{ Año } & \multirow{2}{*}{$\begin{array}{c}\text { Empleo } \\
\text { permanente }\end{array}$} & \multicolumn{2}{|c|}{ Empleo temporal } & \multirow{2}{*}{$\begin{array}{c}\text { Empleo } \\
\text { temporal total }\end{array}$} & $\begin{array}{c}\text { Propietarios, so- } \\
\text { cios y familiares }\end{array}$ & Empleo total \\
\hline 2000 & 369.217 & 80.705 & 80.928 & 161.633 & 3.723 & 534.573 \\
\hline 2001 & 345.564 & 90.713 & 88.476 & 179.189 & 3.269 & 528.022 \\
\hline 2002 & 336.238 & 94.152 & 97.816 & 191.968 & 3.007 & 531.213 \\
\hline 2003 & 330.527 & 97.430 & 114.810 & 212.240 & 3.130 & 545.897 \\
\hline 2004 & 324.515 & 103.623 & 139.462 & 243.085 & 3.255 & 570.855 \\
\hline 2005 & 327.150 & 106.239 & 150.998 & 257.237 & 3.243 & 587.630 \\
\hline 2006 & 333.124 & 107.334 & 168.299 & 275.633 & 3.323 & 612.080 \\
\hline 2007 & 348.698 & 114.505 & 171.203 & 285.708 & 3.215 & 637.621 \\
\hline 2008 & 363.539 & 119.656 & 166.623 & 286.279 & 3.036 & 652.854 \\
\hline 2009 & 369.275 & 117.395 & 151.155 & 268.950 & 3.619 & 641.444 \\
\hline 2010 & 378.550 & 126.112 & 156.826 & 282.938 & 4.068 & 665.556 \\
\hline 2011 & 386.736 & 135.968 & 153.261 & 289.229 & 3.961 & 679.926 \\
\hline 2012 & 387.493 & 148.285 & 136.885 & 285.170 & 3.762 & 676.425 \\
\hline 2013 & 393.642 & 148.095 & 131.730 & 279.825 & 3.416 & 676.883 \\
\hline
\end{tabular}

Fuente: tomado de la encuesta anual manufacturera del DANE

11 Desafortunadamente, debido al nivel agregado de la información del DANE esta no arroja indicios acerca del tipo de intermediario laboral.

12 Se tomó el 2000 como año inicio del periodo de análisis, en razón a que es a partir de este año cuando se acelera la contratación temporal. Pineda (2014) lo atribuye a los coletazos de la crisis de 1999. 
El empleo en el sector manufacturero colombiano ha registrado un aumento sostenido (tabla 4), exceptuando los años 2001 y 2009, con una disminución en los últimos dos años del período de referencia $(2012,2013)$, no tanto como resultado de la caída del empleo permanente, sino por el aumento gradual del empleo temporal, particularmente, hasta 2010, de la contratación indirecta ${ }^{13}$ (tabla 4 y 5), que luego de superar al directo ${ }^{14}$, empezó a rezagarse.

Se conjetura, como ocurre en otros países, que el empleo temporal actúa como amortiguador en las fases cíclicas, tal como se evidenció en la crisis desatada en 2009, cuando se redujo, para recuperarse con posterioridad. Los propietarios, socios y familiares son una categoría funcional de baja incidencia, que se ha mantenido estable.

Tabla 5. Distribución porcentual del empleo industrial en Colombia

\begin{tabular}{|c|c|c|c|c|c|c|}
\hline \multirow{2}{*}{ Año } & \multirow{2}{*}{$\begin{array}{c}\text { Empleo } \\
\text { permanente }\end{array}$} & \multicolumn{2}{|c|}{ Empleo temporal } & Empleo temporal & $\begin{array}{c}\text { Propietarios, socios y } \\
\text { total }\end{array}$ & Emiliares \\
\cline { 3 - 7 } & Directo & Indirecto & Empleo total \\
\hline 2000 & 69,1 & 15,1 & 15,1 & 30,2 & 0,7 & 100,0 \\
\hline 2001 & 65,4 & 17,2 & 16,7 & 33,9 & 0,7 & 100,0 \\
\hline 2002 & 63,3 & 17,7 & 18,4 & 36,1 & 0,6 & 100,0 \\
\hline 2003 & 60,5 & 17,8 & 21,0 & 38,8 & 0,7 & 100,0 \\
\hline 2004 & 56,8 & 18,1 & 24,4 & 42,5 & 0,7 & 100,0 \\
\hline 2005 & 55,7 & 18,1 & 25,7 & 43,8 & 0,5 & 100,0 \\
\hline 2006 & 54,4 & 17,5 & 27,5 & 45,0 & 0,6 & 100,0 \\
\hline 2007 & 54,7 & 17,9 & 26,8 & 44,7 & 0,6 & 100,0 \\
\hline 2008 & 55,7 & 18,3 & 25,5 & 43,8 & 0,5 & 100,0 \\
\hline 2009 & 57,5 & 18,3 & 23,6 & 41,9 & 0,6 & 100,0 \\
\hline 2010 & 56,8 & 18,9 & 23,6 & 42,5 & 0,7 & 100,0 \\
\hline 2011 & 56,9 & 20,0 & 22,5 & 42,5 & 0,6 & 100,0 \\
\hline 2012 & 57,3 & 21,9 & 20,2 & 42,1 & 0,6 & 100,0 \\
\hline 2013 & 58,1 & 21,9 & 19,5 & 41,4 & 0,5 & 100,0 \\
\hline
\end{tabular}

Fuente: elaboración propia con base en la encuesta anual manufacturera del DANE

13 Según la metodología de la Encuesta Anual Manufacturera (EAM), el personal temporal indirecto es aquel que se contrata a través de agencias.

14 El personal temporal directo corresponde al contratado, sin recurrir a intermediarios, por parte del establecimiento. 
Como se observa en la tabla 5 , durante el período de análisis el aporte relativo del empleo permanente se redujo en 11 puntos, reposicionamiento que favoreció al empleo temporal, en particular el indirecto que creció hasta 2011, cuando fue desplazado por el directo, lo que condujo a un incremento en el intervalo de referencia de la misma proporción. Sin embargo, podría afirmarse que existe una equilibrada paridad entre las dos modalidades de contratación, que contrasta con la reducida participación de los propietarios, socios y familiares.

La caída del empleo permanente en 11 puntos, en el período de referencia, hace entrever que esta diferencia fue absorbida por los contratados temporalmente. En 2013 el empleo temporal total ascendió a 41,4\%15.

Parra (2012) coincide con la cifra encontrada en este artículo al estimar el empleo temporal en 41 \%. Con una pequeña diferencia, Pineda (2014) la calculó en 45 \%, nivel que supera los estándares internacionales, por ejemplo, de la Unión Europea que tiene una media, según Vásquez (2013), de 12 \%.

\section{Trayectoria del empleo temporal por categorías funcionales y género}

El vigoroso incremento del empleo temporal en Colombia, como argumentan González y Cuello (2007) y Parra (2012), obedece a que las empresas son más propensas a contratar mano de obra temporal con baja cualificación al implicar costos decrecientes, pero ello también podría sugerir que en la medida en que se contraten trabajadores con mayor cualificación esto supondrá menores requerimientos y gastos de formación o capacitación ${ }^{16}$-que propician mejorías en la productividad-a los que no tendrían acceso, dada la rotación en los puestos y la duración de los contratos.

15 El DANE divulgó recientemente los resultados de la encuesta anual manufacturera de 2014, donde se muestra que el empleo permanente registró una leve recuperación (58,9\%), y, por consiguiente, una reducción del empleo temporal que se situó en 40,6\%.

16 Echeverría (2001) señala que el concepto tradicional de calificación y capacitación ha sido reemplazado por la noción de competencias laborales. 
Tabla 6. Estructura del empleo temporal industrial en Colombia según categorías funcionales ${ }^{17}$

\begin{tabular}{|c|c|c|c|c|c|c|c|c|c|}
\hline \multirow[b]{2}{*}{ Año } & \multicolumn{4}{|c|}{ Empleo temporal directo } & \multicolumn{4}{|c|}{ Empleo temporal indirecto } & \multirow[b]{2}{*}{$\begin{array}{c}\text { Total } \\
\text { Empleo } \\
\text { temporal }\end{array}$} \\
\hline & Obreros & $\begin{array}{c}\text { Profesio- } \\
\text { nales }\end{array}$ & $\begin{array}{c}\text { Admón y } \\
\text { ventas }\end{array}$ & $\begin{array}{l}\text { Total } \\
\text { Empleo } \\
\text { temporal } \\
\text { directo }\end{array}$ & Obreros & $\begin{array}{c}\text { Profesio- } \\
\text { nales }\end{array}$ & $\begin{array}{c}\text { Admón y } \\
\text { ventas }\end{array}$ & $\begin{array}{c}\text { Total } \\
\text { Empleo } \\
\text { temporal } \\
\text { indirecto }\end{array}$ & \\
\hline 2000 & 62.592 & 3219 & 14.894 & & 57.639 & 2328 & 20.961 & 80.928 & 161.633 \\
\hline 2001 & 69.120 & 3930 & 17.663 & 90.713 & 65.980 & 2793 & 19.703 & 88.476 & 179.189 \\
\hline 2002 & 71.626 & 3953 & 18.573 & 94.152 & 74.462 & 3470 & 19.884 & 97.816 & 191.968 \\
\hline 2003 & 73.778 & 4556 & 19.096 & 97.430 & 88.217 & 4052 & 22.541 & 114.810 & 212240 \\
\hline 2004 & 78.498 & 4716 & 20.409 & 103.623 & 107.474 & 5815 & 26.173 & 139.462 & 243.085 \\
\hline 2005 & 80.110 & 4687 & 21.442 & 106.239 & 116.730 & 6600 & 27.668 & 150.998 & 257.237 \\
\hline 2006 & 80.403 & 5815 & 21.116 & 107.334 & 132.540 & 7104 & 28.655 & 168.299 & 275.633 \\
\hline 2007 & 87.073 & 5734 & 88 & 11 & 2 & 7463 & 8 & 17 & 285.708 \\
\hline 2008 & 87.352 & 7303 & 25.001 & 119.656 & 126.540 & 7052 & 33.031 & 166.623 & 286.279 \\
\hline 2009 & 83.829 & 7554 & 26.012 & 117 & 112.431 & 6395 & 32.329 & 151.555 & 268.950 \\
\hline 2010 & 90.865 & 8572 & 26.675 & 126.112 & 116.125 & 8237 & 32.464 & 156.826 & 282.938 \\
\hline 2011 & 98.475 & 9172 & 28.321 & 135.968 & 111.387 & 9401 & 32.473 & 153.261 & 289.229 \\
\hline 2012 & 104.934 & 12.460 & 30.891 & 148.285 & 99.245 & 8086 & 29.554 & 136.885 & 285.170 \\
\hline 2013 & 103.939 & 12.306 & 31.850 & 148.095 & 97.236 & 7718 & 26.776 & 131.730 & 279.825 \\
\hline
\end{tabular}

Fuente: tomado de la encuesta anual manufacturera del DANE.

Como se observa en la tabla 6, la categoría funcional de los obreros ha exhibido, en ambas modalidades de contratación temporal, un crecimiento sostenido a lo largo del período de análisis, que se detuvo solo en 2009 y en el último año -aunque para la indirecta se había anticipado en 2012-, seguido por empleados administrativos que han aumentado ininterrumpidamente en el período de análisis. La vinculación de profesionales temporales tuvo un leve descenso en 2013, lo que no desvirtúa su notorio posicionamiento, manifestación, quizá, de la incorporación de mayores innovaciones tecnológicas, como resultado de las llamadas tecnologías blandas.

17 La encuesta anual manufacturera incluye tres categorías ocupacionales: obreros, operarios y empleados; profesionales, técnicos y tecnólogos, que se agrupan el área de producción, y empleados de administración y ventas. 
Edilberto Rodríguez Araújo - Lina Marleny López Sánchez

Tabla 7. Distribución porcentual del empleo temporal industrial en Colombia según categorías funcionales

\begin{tabular}{|c|c|c|c|c|c|c|}
\hline Año & \multicolumn{3}{|c|}{ Empleo temporal directo } & \multicolumn{3}{c|}{ Empleo temporal indirecto } \\
\hline Obreros & Profesionales & $\begin{array}{c}\text { Admón } y \\
\text { ventas }\end{array}$ & Obreros & Profesionales & $\begin{array}{c}\text { Admón } y \\
\text { ventas }\end{array}$ \\
\hline 2000 & 7,5 & 4,0 & 18,5 & 71,2 & 2,9 & 25,9 \\
\hline 2001 & 76,2 & 4,3 & 19,5 & 74,6 & 3,1 & 22,3 \\
\hline 2002 & 76,1 & 4,2 & 19,7 & 76,1 & 3,5 & 20,4 \\
\hline 2003 & 75,7 & 4,7 & 19,6 & 76,8 & 3,5 & 19,7 \\
\hline 2004 & 75,7 & 4,5 & 19,7 & 77,1 & 4,2 & 18,7 \\
\hline 2005 & 75,4 & 4,4 & 20,2 & 77,3 & 4,4 & 18,3 \\
\hline 2006 & 74,9 & 5,4 & 19,7 & 78,7 & 4,2 & 17,1 \\
\hline 2007 & 76,0 & 5,0 & 19,0 & 78,0 & 4,3 & 17,7 \\
\hline 2008 & 73,0 & 6,1 & 20,9 & 75,9 & 4,2 & 19,9 \\
\hline 2009 & 71,4 & 6,4 & 22,2 & 74,2 & 4,2 & 21,6 \\
\hline 2010 & 72,0 & 6,8 & 21,2 & 74,0 & 5,2 & 20,8 \\
\hline 2011 & 72,4 & 6,7 & 20,9 & 72,7 & 6,1 & 21,2 \\
\hline 2012 & 70,8 & 8,4 & 20,8 & 72,5 & 5,9 & 21,6 \\
\hline 2013 & 70,2 & 8,3 & 21,5 & 73,8 & 5,8 & 20,4 \\
\hline
\end{tabular}

Fuente: elaboración propia con base en la encuesta anual manufacturera del DANE

Pese al predominio de los obreros en la nómina de personal temporal, tal como se evidencia en la tabla 7, en la contratación directa se comprimió en siete puntos, mientras que en la indirecta aumentó dos puntos y medio, duplicándose en los profesionales y nivelándose en ambos tipos en la categoría de personal administrativo, a pesar de que en la modalidad indirecta disminuyó desde el inicio del período de referencia.

De otro lado, el empleo industrial en Colombia tuvo durante el período de análisis un marcado sesgo masculino, dado que alcanzó a representar poco más de $64 \%$, pese a que el empleo femenino creció sostenidamente (tabla 8), excepto, como aconteció con el agregado sectorial, en 2009, punto de quiebre de la expansión que había registrado la actividad manufacturera. El empleo femenino ha decrecido de manera moderada, reactivándose en el último año del período de referencia. 
Tabla 8. Evolución del empleo industrial según género

\begin{tabular}{|c|c|c|c|c|c|}
\hline \multirow{2}{*}{ Año } & \multicolumn{5}{|c|}{ Personal ocupado total } \\
\cline { 2 - 6 } & Hombres & $\%$ & Mujeres & $\%$ & Total \\
\hline 2000 & 334.400 & 62,5 & 200.173 & 37,5 & 534.573 \\
\hline 2001 & 330.756 & 62,6 & 197.266 & 37,4 & 528.022 \\
\hline 2002 & 331.709 & 62,4 & 199.504 & 37,6 & 531.213 \\
\hline 2003 & 339.042 & 62,1 & 206.855 & 37,9 & 545.897 \\
\hline 2004 & 353.943 & 62,0 & 216.912 & 38,0 & 570.855 \\
\hline 2005 & 366.637 & 62,4 & 220.993 & 37,6 & 587.630 \\
\hline 2006 & 386.040 & 63,1 & 226.040 & 36,9 & 612.080 \\
\hline 2007 & 404.883 & 63,5 & 232.738 & 36,5 & 637.621 \\
\hline 2008 & 413.842 & 63,4 & 239.012 & 36,6 & 652.854 \\
\hline 2009 & 410.289 & 64,0 & 231.155 & 36,0 & 641.444 \\
\hline 2010 & 427.816 & 64,3 & 237.740 & 35,7 & 665.556 \\
\hline 2011 & 437.791 & 64,4 & 242.535 & 35,6 & 679.926 \\
\hline 2012 & 437.110 & 64,6 & 239.315 & 35,4 & 676.425 \\
\hline 2013 & 436.823 & 64,5 & 240.060 & 35,5 & 676.883 \\
\hline
\end{tabular}

Fuente: elaboración propia con base en la encuesta anual manufacturera del DANE

A pesar de que a lo largo del período examinado el empleo permanente masculino ha prevalecido, su tendencia hasta mediados de la década pasada fue declinante, para luego retomar la senda de un crecimiento sostenido. Esta situación replicó en el empleo femenino el cual se ha recuperado en 2013. Propietarios, socios y familiares constituyen una categoría residual cuya composición por géneros ha tenido una trayectoria errática (tabla 9).

Tabla 9. Comportamiento del empleo permanente y de propietarios según género

\begin{tabular}{|c|c|c|c|c|c|c|}
\hline \multirow{2}{*}{ Año } & \multicolumn{3}{|c|}{ Empleo permanente } & \multicolumn{3}{c|}{ Propietarios, socios y familiares } \\
\cline { 2 - 7 } & Hombres & Mujeres & Total & Hombres & Mujeres & Total \\
\hline 2000 & 242.994 & 126.223 & 369.217 & 2.421 & 1.302 & 3.723 \\
\hline 2001 & 228.145 & 117.419 & 345.564 & 2.123 & 1.146 & 3.269 \\
\hline 2002 & 220.833 & 115.405 & 336.238 & 1.935 & 1.072 & 3.007 \\
\hline 2003 & 216.939 & 113.588 & 330.527 & 1.956 & 1.174 & 3.130 \\
\hline 2004 & 214.383 & 110.132 & 324.515 & 1.984 & 1.271 & 3.255 \\
\hline 2005 & 216.772 & 110.378 & 327.150 & 2.022 & 1.221 & 3.243 \\
\hline
\end{tabular}


Edilberto Rodríguez Araújo - Lina Marleny López Sánchez

\begin{tabular}{|c|c|c|c|c|c|c|}
\hline \multirow{2}{*}{ Año } & \multicolumn{3}{|c|}{ Empleo permanente } & \multicolumn{3}{c|}{ Propietarios, socios y familiares } \\
\cline { 2 - 7 } & Hombres & Mujeres & Total & Hombres & Mujeres & Total \\
\hline 2006 & 221.110 & 112.014 & 333.124 & 2.043 & 1.280 & 3.323 \\
\hline 2007 & 232.351 & 116.347 & 348.698 & 1.992 & 1.223 & 3.215 \\
\hline 2008 & 239.519 & 124.020 & 363.539 & 1.867 & 1.169 & 3.036 \\
\hline 2009 & 244.575 & 124.700 & 369.275 & 2.241 & 1.378 & 3.619 \\
\hline 2010 & 250.049 & 128.501 & 378.550 & 2.483 & 1.585 & 4.068 \\
\hline 2011 & 255.805 & 130.931 & 386.736 & 2.438 & 1.523 & 3.961 \\
\hline 2012 & 256.878 & 130.615 & 387.493 & 2.263 & 1.499 & 3.762 \\
\hline 2013 & 260.909 & 132.733 & 393.642 & 2.081 & 1.335 & 3.416 \\
\hline
\end{tabular}

Fuente: tomado de la encuesta anual manufacturera del DANE

Asimismo, se observa que, a pesar del empoderamiento del empleo femenino ${ }^{18}$, esta valoración social y laboral es más notoria en el caso de los propietarios, socios y familiares (tabla 10).

Tabla 10. Distribución porcentual del empleo permanente y propietarios según género

\begin{tabular}{|c|c|c|c|c|c|c|}
\hline \multirow{2}{*}{ Año } & \multicolumn{2}{|c|}{ Empleo permanente } & \multirow{2}{*}{ Total } & \multicolumn{2}{|c|}{ Propietarios, socios y familiares } & \multirow{2}{*}{ Total } \\
& Hombres & Mujeres & & Hombres & Mujeres & \\
\hline 2000 & 65,8 & 34,2 & 100,0 & 65,0 & 35,0 & 100,0 \\
\hline 2001 & 66,0 & 34,0 & 100,0 & 64,9 & 35,1 & 100,0 \\
\hline 2002 & 65,7 & 34,3 & 100,0 & 64,3 & 35,7 & 100,0 \\
\hline 2003 & 65,6 & 34,4 & 100,0 & 62,5 & 37,5 & 100,0 \\
\hline 2004 & 66,1 & 33,9 & 100,0 & 60,9 & 39,1 & 100,0 \\
\hline 2005 & 66,3 & 33,7 & 100,0 & 62,3 & 37,7 & 100,0 \\
\hline 2006 & 66,4 & 33,6 & 100,0 & 61,5 & 38,5 & 100,0 \\
\hline 2007 & 66,6 & 33,4 & 100,0 & 61,9 & 38,1 & 100,0 \\
\hline 2008 & 65,9 & 34,1 & 100,0 & 61,5 & 38,5 & 100,0 \\
\hline 2009 & 66,2 & 33,8 & 100,0 & 61,9 & 38,1 & 100,0 \\
\hline 2010 & 66,0 & 34,0 & 100,0 & 61,0 & 39,6 & 100,0 \\
\hline 2011 & 66,1 & 33,9 & 100,0 & 61,5 & 38,5 & 100,0 \\
\hline 2012 & 66,3 & 33,7 & 100,0 & 60,1 & 39,9 & 100,0 \\
\hline 2013 & 66,3 & 33,7 & 100,0 & 60,9 & 39,1 & 100,0 \\
\hline
\end{tabular}

Fuente: elaboración propia con base en la encuesta anual manufacturera del DANE

18 Desafortunadamente la información de la encuesta anual manufacturera no ofrece referencia alguna sobre la estructura etaria de los trabajadores temporales en sus dos grandes vertientes, ni por géneros. 
De lo atrás expuesto se concluye que el empleo temporal indirecto se expandió de manera acelerada hasta 2007, siendo mayor la contratación a término indefinido. En 2009 se produjo una caída de ambas modalidades -aunque el empleo masculino directo, de manera paradójica, repuntó-, para luego recuperarse de forma parcial y revertirse la supremacía del empleo temporal fijo (tabla 11).

Tabla 11. Comportamiento del empleo temporal industrial según género

\begin{tabular}{|c|c|c|c|c|c|c|}
\hline \multirow{2}{*}{ Año } & \multicolumn{2}{|c|}{ Empleo temporal directo } & \multirow{2}{*}{ TOTAL } & \multicolumn{2}{|c|}{ Empleo temporal indirecto } & \multirow{2}{*}{ TOTAL } \\
& Hombres & Mujeres & & Hombres & Mujeres & \\
\hline 2000 & 41.642 & 39.063 & 80.705 & 47.343 & 33.585 & 80.928 \\
\hline 2001 & 46.884 & 43.829 & 90.713 & 53.604 & 34.872 & 88.476 \\
\hline 2002 & 49.453 & 44.699 & 94.152 & 59.488 & 38.328 & 97.816 \\
\hline 2003 & 51.487 & 45.943 & 97.430 & 68.660 & 46.150 & 114.810 \\
\hline 2004 & 54.124 & 49.499 & 103.623 & 83.452 & 56.010 & 139.462 \\
\hline 2005 & 56.283 & 49.956 & 106.239 & 91.560 & 59.438 & 150.998 \\
\hline 2006 & 57.656 & 49.678 & 107.334 & 105.231 & 63.068 & 168.299 \\
\hline 2007 & 61.147 & 53.358 & 114.505 & 109.393 & 61.810 & 171.203 \\
\hline 2008 & 66.054 & 53.602 & 119.656 & 106.402 & 60.221 & 166.623 \\
\hline 2009 & 67.021 & 50.374 & 117.395 & 96.452 & 54.703 & 151.155 \\
\hline 2010 & 74.615 & 51.497 & 126.112 & 100.669 & 56.157 & 156.826 \\
\hline 2011 & 81.267 & 54.701 & 135.968 & 98.281 & 54.980 & 153.261 \\
\hline 2012 & 89.981 & 58.304 & 148.285 & 87.988 & 48.897 & 136.885 \\
\hline 2013 & 88.875 & 59.220 & 148.095 & 84.958 & 46.772 & 131.730 \\
\hline
\end{tabular}

Fuente: elaboración propia con base en la encuesta anual manufacturera del DANE

Como se aprecia en la tabla 11, el empleo temporal femenino, en las dos modalidades de contratación, fue el más afectado por la crisis de 2009, acentuándose, en contraste con el empleo directo, en los años siguientes, la caída de empleo indirecto.

La estructura por género de los dos tipos de contratación temporal muestra el predominio del empleo masculino, tendencia que se acentúa, a expensas del femenino, el que se contrajo drásticamente, en particular desde 2009, poniendo de manifiesto que este sesgo de género es más notorio en el empleo temporal que en el permanente (tabla 12). 
Edilberto Rodríguez Araújo - Lina Marleny López Sánchez

Tabla 12. Distribución porcentual del empleo temporal según género

\begin{tabular}{|c|c|c|c|c|c|c|}
\hline \multirow{2}{*}{ Año } & \multicolumn{2}{|c|}{ Empleo temporal directo } & \multirow{2}{*}{ Total } & \multicolumn{2}{|c|}{ Empleo temporal indirecto } & \multirow{2}{*}{ Total } \\
& Hombres & Mujeres & & Hombres & Mujeres & \\
\hline 2000 & 51,6 & 48,4 & 100,0 & 58,5 & 41,5 & 100,0 \\
\hline 2001 & 51,7 & 48,3 & 100,0 & 66,2 & 33,8 & 100,0 \\
\hline 2002 & 52,5 & 47,5 & 100,0 & 60,8 & 39,2 & 100,0 \\
\hline 2003 & 52,8 & 47,2 & 100,0 & 59,8 & 40,2 & 100,0 \\
\hline 2004 & 52,2 & 47,8 & 100,0 & 59,8 & 40,2 & 100,0 \\
\hline 2005 & 53,0 & 47,0 & 100,0 & 60,6 & 39,4 & 100,0 \\
\hline 2006 & 53,7 & 46,3 & 100,0 & 62,5 & 37,5 & 100,0 \\
\hline 2007 & 53,0 & 47,0 & 100,0 & 63,9 & 36,1 & 100,0 \\
\hline 2008 & 55,2 & 44,8 & 100,0 & 63,8 & 36,2 & 100,0 \\
\hline 2009 & 57,1 & 42,9 & 100,0 & 63,8 & 36,2 & 100,0 \\
\hline 2010 & 59,2 & 40,8 & 100,0 & 64,2 & 35,8 & 100,0 \\
\hline 2011 & 59,8 & 40,2 & 100,0 & 64,1 & 35,9 & 100,0 \\
\hline 2012 & 60,7 & 39,3 & 100,0 & 64,3 & 35,7 & 100,0 \\
\hline 2013 & 60,0 & 40,0 & 100,0 & 64,5 & 35,5 & 100,0 \\
\hline
\end{tabular}

Fuente: elaboración propia con base en la encuesta anual manufacturera del DANE

De otro lado, al analizar las diversas categorías funcionales, se constata el peso dominante del género masculino, en las dos modalidades de contratación, en la categoría de obreros, y parcialmente, en la de profesionales, en lo relacionado con el empleo temporal directo. Se destaca que durante el período de análisis, las mujeres aventajan a los hombres en las funciones de administración y ventas, tanto en el empleo temporal directo como en el indirecto.

Tabla 13. Empleo temporal según categorías funcionales y género

\begin{tabular}{|c|c|c|c|c|c|c|c|c|}
\hline \multirow{2}{*}{$\begin{array}{c}\text { Categoría de personal } \\
\text { temporal }\end{array}$} & \multicolumn{3}{|c|}{ Directo } & \multicolumn{4}{c|}{ Indirecto } \\
\cline { 2 - 10 } & \multicolumn{2}{|c|}{ Hombres } & \multicolumn{2}{c|}{ Mujeres } & \multicolumn{2}{c|}{ Hombres } & \multicolumn{2}{c|}{ Mujeres } \\
\cline { 2 - 10 } & 2000 & 2013 & 2000 & 2013 & 2000 & 2013 & 2000 & 2013 \\
\hline Obreros & 32.787 & 64.499 & 29.805 & 39.440 & 36.183 & 64.499 & 21.456 & 28.953 \\
\hline Profesionales & 2333 & 886 & 8.372 & 3062 & 1660 & 5628 & 668 & 2090 \\
\hline $\begin{array}{c}\text { Empleados de admón. y } \\
\text { ventas }\end{array}$ & 6522 & 12.306 & 8.372 & 15.132 & 9.500 & 11.047 & 11.461 & 15.729 \\
\hline
\end{tabular}

Fuente: tomado de la encuesta anual manufacturera del DANE 
No obstante estos indicios de un gradual empoderamiento laboral de las mujeres en estas labores, como la han revelado las estadísticas del mercado laboral, en lo referente a desempleo y subempleo subjetivo, la población más vulnerable son las mujeres. Esta situación no ha sido objeto de políticas laborales diferenciadas que mitiguen esta desigualdad de oportunidades.

Por último, al examinar la razón empleo femenino temporal indirecto/empleo masculino temporal en las dos modalidades de contratación, se aprecia que existe una brecha muy marcada. Si a comienzos de la década del 2000 este diferencial reflejaba el empoderamiento femenino, en el transcurso de esta década esta tendencia se revirtió de manera acelerada, en particular, en la contratación directa.

Esta brecha se fue ensanchando, hasta situarse la ventaja masculina frente a la femenina, en 2013, once (11) puntos por encima de la femenina. Lo anterior sugeriría que la prevalencia de género a favor de los hombres en la contratación a término fijo se ha ido afianzando, lo que significa una regresión en la equidad de género laboral. La relación empleo femenino/empleo masculino en la contratación a término indefinido pasó de 93,8 a 66,6 en el periodo de análisis, mientras que a término definido descendió de 70,9 a 55,0.

Tabla 14. Relación empleo temporal según género ${ }^{19}$

\begin{tabular}{|c|c|c|}
\hline Año & Empleo Temporal Directo & Empleo Temporal Indirecto \\
\hline 2000 & 93,8 & 70,9 \\
\hline 2001 & 93,5 & 65,0 \\
\hline 2002 & 90,4 & 64,4 \\
\hline 2003 & 89,2 & 69,2 \\
\hline 2004 & 91,4 & 67,1 \\
\hline 2005 & 88,7 & 64,9 \\
\hline 2006 & 86,2 & 59,9 \\
\hline 2007 & 87,3 & 56,5 \\
\hline 2008 & 81,1 & 56,6 \\
\hline 2009 & 75,2 & 56,7 \\
\hline 2010 & 69,0 & 55,8 \\
\hline 2011 & 67,3 & 55,9 \\
\hline 2012 & 64,8 & 55,6 \\
\hline 2013 & 66,6 & 55,0 \\
\hline
\end{tabular}

Fuente: elaboración propia con base en la encuesta anual manufacturera del DANE

19 Esta relación, propuesta en este artículo, mide la proporción del empleo temporal femenino directo comparado con el empleo temporal directo masculino. Asimismo, se compara el empleo temporal femenino indirecto con su componente masculino. 


\section{CONCLUSIONES}

La transición del modelo tecnoproductivo fordista al postfordista trajo consigo nuevas formas de organización del trabajo. La flexibilización laboral y la tercerización resultante son procesos que se han extendido por toda la economía globalizada. En Colombia el fenómeno de tercerización se remonta a la década de 1990 -coincidiendo con la apertura económica-, y una de sus principales manifestaciones es la creciente contratación de trabajadores y empleados a término fijo, ya sea, de forma directa por el establecimiento, o, a través de empresas de servicios temporales o cooperativas. La legislación que se ha expedido ha sido muy laxa, lo que ha permitido abusos por parte de quienes triangulan la contratación.

En la industria colombiana el empleo remunerado se estancó, a pesar del aumento de los establecimientos fabriles y de la producción sectorial. El año 2009 fue el punto de inflexión cuando se comprimieron el empleo y la producción manufacturera.

No obstante que el empleo permanente industrial ha crecido de manera sostenida, incluso en 2009, el personal contratado a término definido ha repuntado, hasta representar más del 41 \%, mientras el permanente descendió, en términos relativos, once puntos. Como lo ilustra la experiencia internacional, el empleo a término fijo cumple una función amortiguadora durante el ciclo económico.

A escala nacional el empleo temporal indirecto apunta a equipararse al directo, aunque, después de superarlo hasta 2011, se ha menguado.

Dentro de las categorías funcionales que integran el empleo temporal industrial en Colombia, los obreros y operarios sobrepasaron, tanto los contratados de manera directa como bajo la modalidad indirecta, el $70 \%$. A diferencia de los indirectos que alcanzaron el $73,8 \%$, se registró un descenso en los directos, que se situaron en $70,2 \%$. Mientras el punto de quiebre de los directos fue 2008, para luego retomar su senda de crecimiento, para los indirectos fue 2007, contrayéndose en el resto del intervalo. De las dos categorías restantes, la de mayor representatividad fue la de profesionales vinculados al proceso productivo.

El empleo masculino ha predominado en el período de análisis; en contraste, el femenino se ha estabilizado, hasta representar un poco más de una tercera parte del personal ocupado. Reflejo del sesgo existente en la composición por género, tanto en la contratación permanente como en la temporal los hombres superan a las mujeres. Desde 2010 las mujeres contratadas a término fijo por los establecimientos industriales aumentaron, mientras que las tercerizadas se redujeron. De igual forma, la composición por género de las categorías funcionales reveló el peso dominante de los hombres. La única categoría en la que se registró un reposicionamiento del 
empleo femenino temporal fue el área de administración y ventas. Lo anterior no desvirtúa la regresión observada en la equidad de género laboral, y, por consiguiente, la conveniencia de políticas públicas de género con enfoque diferenciado.

Se concluye que la creación de empleo estable, es decir, permanente se ha elevado, mientras que el temporal lo ha hecho a mayor ritmo, pese a la caída observada en 2013, como resultado de la pérdida de importancia del empleo indirecto. Es previsible que, a pesar del moderado crecimiento de la temporalidad, esta continuará expandiéndose, aún más, en las condiciones de una industria estancada, que, por consiguiente, induce estrategias de reestructuración, mediante mayor flexibilización de las relaciones de trabajo.

\section{BIBLIOGRAFÍA}

ANDI (2015). Estrategia para una nueva industrialización. Bogotá: Editorial Nomos S. A., 315 p.

Añez, Carmen (2012). Subcontratación y triangulación laboral: relaciones encubiertas. En: Revista Venezolana de Análisis de Coyuntura, vol. XVIII, No. 2, junio-diciembre, Universidad Central de Venezuela, Caracas, pp. 163-177.

Ariza, Natalia (2011). Elementos de discusión sobre trabajo temporal e indirecto. Resultados de la encuesta social longitudinal de Fedesarrollo 2010 trabajo temporal e indirecto y sus implicaciones sobre el mercado laboral, En: Debates de Coyuntura Económica y Social, N. ${ }^{\circ}$ 89, Bogotá, Fedesarrollo, noviembre, pp. 20-26.

Baró, Ezequiel (2013). ¿Desindustrialización o metamorfosis de la industria? En: Revista Economía Industrial, N. ${ }^{\circ}$ 387, Madrid, pp. 33-47.

CSA-CSI (2013). Tercerización mediante agencia de trabajo temporal en América Latina. Sao Paulo.

Clavijo, Sergio; Vera, Alejandro y Fandiño, Alejandro (2012). La desindustrialización en Colombia, Bogotá: ANIF, Centro de Estudios Económicos.

Clavijo, Sergio; Vera, Alejandro y Fandiño, Alejandro (2013). Desindustrialización en Colombia. ¿Qué hacer ahora? En: Carta Financiera, ANIF, Bogotá, pp. 13-22.

De La Garza, Enrique (2012). La subcontratación y la acumulación de capital en el nivel global. En La subcontratación laboral en América Latina: miradas multinacionales (Juan Carlos Celis, coordinador), Medellín, Ediciones CLACSO-ENS, pp. 15-37.

Durán, Julián (2012). Recomposición de la estructura productiva y generación de empleo en la economía colombiana 1990-2007. En Magazín Empresarial, vol. 8, ․․ 17, Facultad de Ciencias Económicas y Empresariales, Universidad Santiago de Cali, pp. 49-56.

Echeverría, Magdalena (2001). Empresas de empleo temporario, mercado laboral y formación para el trabajo. Santiago de Chile, CEPAL-GTZ.

Farné, Stefano (2012). La calidad del empleo y la flexibilidad laboral en Colombia. En: La calidad del empleo en América Latina a principios del siglo XXI, Stefano Farné (compilador). Bogotá: Universidad Externado de Colombia, pp.119-161. 
FEDESARROLLO (2011). Trabajo temporal e indirecto. ¿Quiénes son? ¿Dónde están? ¿Cuáles son sus condiciones laborales? En: Tendencia Económica, Informe Mensual de Fedesarrollo, N. 11 , noviembre, Bogotá, pp. 5-11.

González, María Candelaria (2006). Flexibilidad de las relaciones laborales. Una perspectiva teórica posfordista. En: Revista Gaceta Laboral, Vol. 12, N.․ 1, Universidad del Zulia, pp. 33-68.

González, María Inmaculada y Cuello de Oro, Diego (2007). Análisis de los factores explicativos del empleo de trabajadores temporales en las empresas españolas. En: Documento de

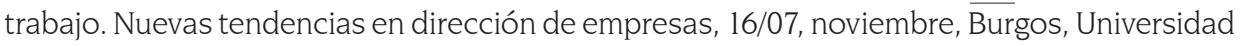
de Burgos, pp. 1-38.

Iranzo, Consuelo y Richter, Jackeline (2012). Las implicaciones de la subcontratación laboral, pp. 39-65.En:: Celis, Juan Carlos (coord.) (2012). La subcontratación laboral en América Latina: miradas multinacionales, Medellín, Ediciones CLACSO- ENS, 420Pp.

Katz, Jorge (2007). Cambios estructurales y desarrollo económico, ciclos de creación y destrucción de capacidad productiva y tecnológica en América Latina. En: Revista de Economía Política de Buenos Aires n. ${ }^{\circ}$ 1, Buenos Aires, pp. 71-92.

López, Lina Marleny (2010). Tercerización y cooperativas de trabajo asociado en el Hospital San Rafael de Tunja. En: Revista Apuntes del Cenes, vol. XXIX, N. ${ }^{\circ} 49$, I semestre, Universidad Pedagógica y Tecnológica de Colombia, Tunja, pp. 179-206.

Moncayo, Edgard (2008). Cambio estructural: trayectoria y vigencia de un concepto. En:: Revista CIFE N. ${ }^{\circ}$ 13, Universidad Santo Tomás, Bogotá, pp. 235-249.

Moncayo, Edgard (2011). Cambio estructural, crecimiento e industrialización en América Latina 1950-2005, Universidad Nacional de Colombia, Facultad de Ciencias Económicas, mayo. Bogotá: Programa de Doctorado en Ciencias Económicas, 213p.

Neffa, Julio César (1999). Crisis y emergencia de nuevos modelos productivos. En: Los retos teóricos de los estudios del trabajo hacia el siglo XXI, Buenos Aires: CLACSO, pp. 39-70.

OIT (2015). Perspectivas sociales y del empleo en el mundo. El empleo en plena mutación. Resumen ejecutivo. Ginebra: OIT, 7p.

ONUDI (2013). Informe sobre el desarrollo industrial 2013. La creación sostenida del empleo: el rol de la industria manufacturera y el cambio estructural, Resumen, 29p.

Parra, Mónica (2012). Trabajo temporal e indirecto: la pieza que faltaba para entender el mercado laboral colombiano. Premio Germán Botero de los Río. Bogotá: Fedesarrollo, 70p

Pineda, Javier (2014). El sesgo antilaboral del desarrollo colombiano y las políticas laborales. Bogotá: Fescol, 32p.

Quevedo, Eduardo (2000). Reestructuración, flexibilidad y trabajo en América Latina. En: Papeles de población, vol. 6, N. 26, octubre-diciembre, Universidad Autónoma del Estado de Toluca, Toluca, México, pp. 88-107.

Ramírez, Juan Carlos (2011). Elementos de discusión sobre el trabajo temporal y tercerizado. Resultados de la encuesta social longitudinal de Fedesarrollo 2010 trabajo temporal e indi- 
recto y sus implicaciones sobre el mercado laboral. En: Debates de Coyuntura Económica y Social, N. ${ }^{\circ}$ 89, Fedesarrollo, noviembre, Bogotá, pp. 38-40.

Rodríguez, Edilberto (2010). Los orígenes de la desindustrialización colombiana. En: Revista Apuntes del Cenes, vol. XXIX, No. 50, Il semestre, Universidad Pedagógica y Tecnológica de Colombia, Tunja, pp. 43-72.

Romo, David y Musik, Guillermo (2005). El concepto de competitividad. En: Revista Comercio Exterior, vol. 55, N. ${ }^{\circ}$, marzo, México, pp. 200-214.

Safón, Vicente (1997). ¿Del fordismo al posfordismo? El advenimiento de los nuevos modelos de organización industrial. En: Congreso de Ciencia Regional de Andalucía, Jerez de la Frontera, pp. 310-318.

Salama, Pierre (2012). Globalización comercial: desindustrialización prematura en América Latina e industrialización en Asia. En: Revista Comercio Exterior, Vol. 62, N. 6 noviembre y diciembre, México, pp. 34-44.

Sánchez, Roberto (2012). Características de producción y empleo en la industria en Colombia. En: La Plata: VII Jornada de Sociología de la Universidad Nacional de La Plata, 19p.

Vásquez, Héctor (2013). Una mirada al trabajo temporal en Colombia y a las empresas de servicios temporales. Medellín: ENS, Agencia de Información Sindical, 7p.

\section{REFERENCIAS JURÍDICAS Y OTROS DOCUMENTOS}

ACOSET (2015). Observatorio del mercado laboral, Informe estadístico a junio de 2015.

ACRIP y Fedesarrollo (2013). La tercerización laboral en Colombia. En: Informe mensual del mercado laboral, Bogotá: Fedesarrollo, agosto, pp. 1-6.

Código Sustantivo del Trabajo (CST). Adoptado por el Decreto 2663 de 5 de agosto de 1950. Bogotá D. E.

CONFECOOP (2013). Desempeño sector cooperativo colombiano, Bogotá.

Congreso de Colombia (1990). Ley 50. Por la cual se introducen reformas al Código Sustantivo del Trabajo y se dictan otras disposiciones. Bogotá D. E., diciembre 28.

Congreso de Colombia (1990). Ley 60. Por la cual se reorganiza el Sistema Nacional de Salud y se dictan otras disposiciones. Bogotá D. E., diciembre 28.

Congreso de Colombia (1991) Ley 10. Por la cual se regulan las empresas asociativas de trabajo. Bogotá, enero 21.

Congreso de la República de Colombia (1993). Ley 100. Por la cual se crea el sistema de seguridad social integral y se y se dictan otras disposiciones. Bogotá, diciembre 23.

Congreso de Colombia (2002). Ley 789. Por la cual se dictan normas para apoyar el empleo y ampliar la protección social y se modifican algunos artículos del Código Sustantivo de Trabajo. Bogotá D. C., diciembre 27. 
Congreso de Colombia (2003). Ley 797. Por la cual se reforman algunas disposiciones del sistema general de pensiones previsto en la Ley 100 de 1993 y se adoptan otras disposiciones sobre los Regímenes Pensionales exceptuados y especiales. Bogotá D. C., enero 29.

Congreso de Colombia (2010). Ley 1429. Por la cual se expide la ley de formalización y generación de empleo. Bogotá D. C., diciembre 29.

Congreso de Colombia (2008). Ley 1221. Por la cual se establecen normas para promover y regular el teletrabajo y se dictan otras disposiciones. Bogotá D. C., julio 16.

Congreso de la República de Colombia (2012). Ley 1607. Por la cual se expiden normas en materia tributaria y se dictan otras disposiciones. Bogotá D. C., diciembre 26.

Congreso de Colombia (2013). Ley 1610. Por la cual se regulan algunos aspectos sobre las inspecciones del trabajo y los acuerdos de formalización laboral. Bogotá D. C., enero 02.

Ministerio de la Protección Social (2006). Decreto 4369. Por el cual se reglamenta el ejercicio de la actividad de las Empresas de Servicios Temporales y se dictan otras disposiciones. Bogotá D. C., diciembre 04.

Ministerio de Trabajo (2015). Registro de Empresas de Servicios Temporales, Bogotá.

Presidencia de la República (1990). Decreto 468. Por el cual se reglamenta las normas correspondientes a las cooperativas de trabajo asociado contenidas en la Ley 79 de 1988 y se dictan otras disposiciones sobre el trabajo cooperativo asociado. Bogotá D. E., febrero 23.

Presidencia de la República (2006). Decreto 4588. Por el cual se reglamenta la organización y funcionamiento de las cooperativas y precooperativas de trabajo asociado. Bogotá D. C., diciembre 27.

Presidencia de la República (2012). Decreto 0884. Por medio del cual se reglamenta la Ley 1221 de 2008 y se dictan otras disposiciones. Bogotá D. C, abril 30. 